\section{(2) OPEN ACCESS}

\title{
Barriers to dementia diagnosis and care in China
}

\author{
Zara Quail, ${ }^{1}$ Angelina Wei, ${ }^{2}$ Vicky Fan Zhang, ${ }^{2}$ Mark McLean Carter (1) 1,2
}

${ }^{1}$ Care Visions Healthy Ageing, Care Visions Limited, Stirling, UK ${ }^{2}$ Care Visions Dementia Services, Care Visions China, Beijing, China

\section{Correspondence to}

Mr Mark McLean Carter; mark.carter@carevisions.co.uk

Accepted 20 February 2020
Check for updates

(c) BMJ Publishing Group Limited 2020. Re-use permitted under CC BY-NC. No commercial re-use. See rights and permissions. Published by BMJ.

To cite: Quail Z, Wei A Zhang VF, et al. BMJ Case Rep 2020;13:e232115. doi:10.1136/bcr-2019232115

\section{SUMMARY}

In China, the ageing population and the prevalence of dementia are projected to escalate significantly by 2050 resulting in a substantial increase in health and economic burden on caregivers, healthcare facilities, healthcare providers and communities. There is no published national dementia policy or strategy in China. This case report describes significant barriers contributing to diagnostic problems and inadequate care of dementia through the case of an older female in rural China, whose condition deteriorated due to neuropsychiatric and functional symptoms of undiagnosed dementia. Intersectoral collaboration between care organisations facilitated delivery of a non-pharmacological intervention programme which was associated with improvements in the patient's functional and neuropsychiatric symptoms. The case demonstrates that recruitment and training of a wider range of health and care professionals and caregivers in a systematic approach to nonpharmacological interventions could help overcome barriers to the specialised care needs of people with dementia where resources are lacking.

\section{BACKGROUND}

Dementia is a group of serious and debilitating neurological conditions which cause progressive deterioration in a person's cognition, behaviour and function resulting in complex care needs, particularly as dementia progresses. ${ }^{12}$ Ageing is the most significant risk factor for dementia. ${ }^{1}$ Population ageing and dementia are increasingly being recognised as global priorities, especially in low/middle-income countries. ${ }^{3}$ However, it was only in 2019 at the G20 summit in Osaka, Japan, that the Leaders' Declaration included the agreement to promote healthy and active ageing and implementation of policies to address dementia including risk reduction, sustainable long-term care and inclusive societies to improve quality of life for people with dementia and their caregivers. ${ }^{4}$ The WHO notes that 15 of the 17 United Nations sustainable development goals are applicable to ageing, and if the goals are met, population ageing will further increase. ${ }^{5}$ With advanced ageing, globally it is anticipated that serious health-related suffering for people with dementia will increase by $264 \%$ between 2016 and 2060, which will also result in the need for increased resources to care for people with advanced dementia and at end of life. ${ }^{6}$ Global healthcare workforce projections demonstrate a clear lack of available staff to support the diagnosis and increasing care needs of people with dementia.
Of the global population in 2017, nearly one in four people over the age of 60 lived in China where the population of those over 60 is expected to increase from about 228.9 million $(16.2 \%$ of the population) in 2017 to 478.9 million (35.1\% of the population) by $2050{ }^{8}$ China also has the largest population of people over the age of 80 and the number of people in this age group is projected to increase fourfold by $2050 .{ }^{89}$ It is anticipated that by 2050, 66 million people in China over the age of 60 will be care dependent, requiring daily care assistance. ${ }^{9}$ Currently about one fifth $(9.48$ million) of the globally estimated 50 million people living with dementia live in China where the prevalence of dementia is projected to increase from 14.1 million in 2020 to 23.3 million people in $2030 .^{31011}$ As a result of the escalating dementia prevalence, there is a substantial expected increase in health and economic burden on caregivers, healthcare facilities, healthcare providers and communities. ${ }^{12}$ Overall estimated dementia care costs in China are predicted to escalate from US $\$ 47.2$ billion in 2010 to US $\$ 114.2$ billion in 2030 , which will likely outpace China's economic development. ${ }^{11}$ In China, there is national level recognition for legislation and policy on ageing and services for elderly care as set out in the 12th and 13th Five Year Plans for Economic and Social Development for the People's Republic of China. ${ }^{13}{ }^{14}$ Alzheimer's disease is one of the conditions listed in the China Central Government National Five-year Plan for Mental Health and other national policies and legislation have prioritised provision of long-term care for older people. ${ }^{15-20}$ The China National Committee on Ageing, as the secretariat for the China National Working Commission on Ageing, is tasked with the development of policies, strategies and plans for ageing on a national level; however neither these groups nor any national Alzheimer's or dementia societies active in China have published a national dementia policy or strategy. ${ }^{21}$ With the rapidly increasing rates of care dependence in China, there is a more urgent need for innovative solutions to providing dementia diagnosis and quality care within communities and care facilities. ${ }^{69112223}$

China has one of the highest rates of undetected dementia with studies demonstrating that over $90 \%$ of dementia cases remain undiagnosed. ${ }^{24}{ }^{25}$ For dementia diagnosis and care planning, it is recognised that the optimal approach is early access to assessment and diagnosis to confirm the dementia subtype and investigate other potential symptom causes, comorbidities and initiate early interventions. ${ }^{26}$ The patient in this case report was eventually diagnosed with Alzheimer's disease, 
the most common cause of dementia, accounting for about $63 \%$ of diagnosed dementia cases in China. ${ }^{27}$ Early definitive diagnosis of Alzheimer's disease as well as other causes of dementia including cerebrovascular disease, Lewy Body disease, frontotemporal lobar degeneration, Parkinson's disease and mixed pathologies, allows for more appropriate patient management planning and modification of secondary risk factors. ${ }^{1}$ While the data and case history discussed in this report relate to China, the prevalence of dementia is increasing in other low/ middle-income countries. ${ }^{3}$ With no pharmacological cure for dementia, and significant potential side effects from medications prescribed for cognition and behavioural and psychological symptoms, early access to optimal dementia diagnosis and care planning are important global health challenges. ${ }^{3} 22$ Individual non-pharmacological interventions have been shown to improve cognition, reduce neuropsychiatric symptoms of dementia, are cost-effective and can be applied as early-stage interventions as well as in more advanced stages of dementia. ${ }^{29-31}$

The patient, her family and care providers had to overcome numerous barriers to obtain a dementia diagnosis and facilitate her increasingly complex care needs in advanced dementia. There are social, economic and political barriers to accessing services for people living with dementia in China. However, a move to address these barriers is starting to be seen with the development of more widespread policies on aged care. This case highlights the numerous current social and healthcare system barriers to dementia diagnosis and care in China which we discuss in the context of accessibility, availability, affordability, adequacy, acceptability and awareness. ${ }^{32-35}$ We also describe how some barriers to adequate advanced-stage dementia care were overcome through intersectoral collaboration between a nursing home and a third-party dementia social care provider to deliver a non-pharmacological dementia care programme.

\section{CASE PRESENTATION}

A female patient in her mid-60s had been living with her husband and her dog in a rural town in Inner Mongolia. Her husband had noticed deterioration in the patient's memory, mood and ability to care for herself and he was no longer able to manage her care in their own home. Their only daughter lived in southern China where she worked and had her own family responsibilities, and as a result was not able to assist with the patient's care. The patient's husband therefore sought out a domestic helper willing to live in with the patient and provide support. The domestic helper lived in a rural town in northern China and so the patient's husband had to move the patient along with her dog more than 350 miles away from the family home to a rented house in the domestic helper's town. ${ }^{36}$ The patient subsequently became entirely dependent on the domestic helper to assist her with all activities of daily living including walking. The patient's memory deficit resulted in her no longer being able to recognise her husband and daughter or the domestic helper. The patient was confused and was disoriented to person, date, time and place. Significant neuropsychiatric symptoms included emotional dysregulation, increased agitation noted particularly in the mornings and around mealtimes, and auditory and visual hallucinations. Periods of agitation were accompanied by repetitive movements such as scratching her scalp and arms, pulling her hair, rubbing her hands, and repeatedly touching her tongue. She would also scold and curse at family members and the domestic helper. The patient, who was unable to describe the hallucinations, would scream or call out for her parents when experiencing them. She required adult incontinence pants due to urinary and faecal incontinence. The patient was on soft diet as she was edentulous and a baby bottle with milk formula was being used to feed her. However, the patient would resist feeding by hitting the helper, spitting out the food and repeatedly shouting. She would sometimes choke on the formula due to her constant talking during mealtimes. This patient's diet had deteriorated due to feeding difficulties as her condition progressed. Her premorbid diet was not known. Due to the helper's concerns for the patient's safety, she had been kept her in bed and a grade 1 sacral pressure sore had developed.

In considering the patient's biopsychosocial history and dementia risk factors, the patient had no family history of dementia nor any known genetic risk factors. However, females have a higher risk of dementia diagnosis and symptom severity as the disease progresses. ${ }^{37}$ The patient did have a previous history of depression but no other psychiatric conditions. Depression is both a risk factor and a symptom for dementia. ${ }^{38}$ The patient had no history of hypertension, other cardiovascular disease, diabetes or stroke. ${ }^{38}$ The patient had osteoporosis which is both an associated potential risk factor for dementia and an increased risk for bone fracture. ${ }^{39} 40$ She had never smoked and did not drink alcohol. She had been living away from her family in a different rural city with only her dog and a paid domestic worker for interaction. Social isolation and loneliness are both dementia risk factors and symptoms which may also be associated with symptoms of depression. ${ }^{38}$

Two years after her initial deterioration, in 2016 the patient was finally diagnosed with Alzheimer's disease when the family's growing concern for her progressively deteriorating condition prompted the decision to take the patient to an acute hospital in Beijing for assessment. The patient had to travel over 400 miles, ${ }^{36}$ an 8 -hour journey by car, accompanied by her husband and daughter (who had to take time off work), for further assessment and diagnosis as a hospital in-patient. Following diagnosis, the patient was prescribed five different traditional Chinese medicines for sedation, stress relief and stimulation of the mind. No anticholinergic or neuropsychiatric medication was prescribed at the time. The patient returned to her rented house with her dog and domestic helper but her deteriorating symptoms were beyond the capabilities of the domestic helper who had no previous experience in caring for people with dementia. As a result, in late 2018, the family admitted the patient to a nursing home with a dedicated dementia ward in a town in Inner Mongolia. After the patient's admission to the nursing home, despite the prescription of quetiapine and lorazepam by the facility doctor, the nursing home staff experienced numerous challenges in caring for the patient especially due to her neuropsychiatric symptoms. Specialised dementia care is rare in China and in this nursing home, there were no structured care plans or programmes for people with dementia. ${ }^{33}$ Due to the ongoing difficulties in managing the patient, the nursing home contacted our dementia social care organisation to request assistance with a management plan in a collaborative effort to provide advanced dementia care.

Our dementia social care team provided a multicomponent dementia social care programme for the patient which included:

- An in-depth needs assessment leading to a focused, practical care plan which was discussed with the patient's family and nursing home staff.

- Strategies and non-pharmacological interventions to manage or better cope with the patient's symptoms of dementia focusing on management of the neuropsychiatric symptoms and improving activities of daily living and nutritional intake. 
- Where appropriate, social activities targeted at reducing social isolation and loneliness.

- Dementia education for the nursing home staff.

At initial assessment in late 2018, the patient's Clinical Dementia Rating (CDR) Scale was $3,{ }^{41}$ and Global Deterioration Scale/Functional Assessment Staging (GDS/FAST) was 6/6.8, ${ }^{42}$ which confirmed the patient had severe cognitive impairment and advanced symptoms of Alzheimer's disease. The patient's minimental state examination (MMSE) was scored at 0 but co-operation for cognitive testing was difficult due to the patient's significant neuropsychiatric symptoms at the time and as a result it was not possible to determine if this was an accurate reflection of her cognitive function. ${ }^{43-45}$ A multicomponent care plan was implemented which included at least 1 hour a day of nonpharmacological activities aimed at support and, where possible, rehabilitation of the behavioural and psychological, cognitive, functional, physical and nutritional domains of the patient's symptoms. Social isolation was prominent in this case and one of our aims was to encourage social participation to improve her quality of life. Non-pharmacological intervention activities applied included music, ${ }^{29} 3046$ art, ${ }^{47}$ aromatherapy, ${ }^{30}$ doll therapy, ${ }^{48}$ light therapy, ${ }^{49}$ validation therapy,${ }^{50}$ talking therapy, ${ }^{51}$ food therapy, ${ }^{52}$ cognitive training, ${ }^{29}$ reality orientation, ${ }^{29} 50$ physiotherapy, fine motor skill training and rehabilitation of activities of daily living. ${ }^{30}$ The selection of non-pharmacological interventions was guided by a structured cognitive intervention pathway which had been developed by the dementia social care organisation as part of their dementia care model. A weekly report with updates and videos of the patient was sent to the family. The musical activities were noted initially to have the best response of all the interventions and were associated with reduced agitation and associated repetitive movements and fewer hallucinations. Her mood also appeared to be uplifted by the art, light (sunbathing) and food activities as evidenced from a less blunted affect, more smiling, reduced agitation, fewer hallucinations and fewer verbal outbursts during sessions. Aromatherapy with lavender and lemon balm and the introduction of a doll to hold were also associated with reduced agitation during sessions. The dolls and a music player were available in the patient's room at all times as a means of comfort during episodes of agitation or distress. Talking and cognitive activities were associated with an improvement in the patient's communication skills in that she was able to again introduce herself to people, hold a basic conversation and communicate some of her needs which, in turn, contributed to improved socialisation. Reality orientation strategies included use of a white board in her room for date and time, daily medication, mealtime and sleep schedules, and planned social activities. In terms of rehabilitation of activities of daily living, by January 2019, the patient was able to dress herself, button up her clothes, comb her hair, wash her hands, fold clothes after undressing, walk unaided along the corridor of the nursing home and was able to climb stairs with assistance. During mealtimes, she no longer shouted or hit out at the team members nor had any further episodes of choking and by April 2019 was able to feed herself again. By this stage, the patient was able to sit up in bed unaided as well as move to and from a chair unaided. She continues to need assistance to use the toilet. With the use of barrier cream and frequent assistance to turn the patient, the sacral pressure sore was completely healed by mid-April 2019.

In May 2019, as expected, the CDR and GDS/FAST scores remained the same over the 6 months. The patient's Barthel Index of Activities of Daily Living scale score improved from 15 to 25 between December 2018 and May 2019. ${ }^{53}$ Overall, there was an observed reduction in the frequency of neuropsychiatric symptoms of agitation, associated repetitive movement, hallucinations and feeding resistance within the first 2 months. It was however noted after the patient had a 2 -week admission to hospital for pneumonia that her neuropsychiatric symptoms of agitation and hallucinations escalated again. It is known that non-elective hospital admission is associated with deterioration in symptoms of dementia after discharge. ${ }^{54}$ In terms of cognition, an MMSE was re-attempted but again a low score of 1 was affected by difficulty in participating in the test and continued significantly reduced verbal skills. The patient still did not recognise her husband, daughter and dog at a family visit but appeared to enjoy the time with them. The overall improvement was most noticeable for activities of daily living and reduced frequency of neuropsychiatric symptoms. While it is not entirely clear why there was no improvement in cognition along with the activities of daily living, it is speculated that, because this patient had been confined to bed at home due to her worsening neuropsychiatric symptoms, she may have not been able to preserve activities of daily living some of which were rehabilitated with support from the care staff.

The social care team continue to work with the patient who was noted to express, unprompted, that she felt happy whenever she saw one of the social care team members. The family indicated that they were very satisfied with the care provided by the combined efforts of the nursing and social care teams and the nursing home facility has given positive feedback about the dementia programme delivered. Our team also provided training on dementia and the non-pharmacological interventions applied to help manage the patient's neuropsychiatric symptoms and feeding difficulties. As a result, the nursing home staff reported that their confidence in managing patients with dementia has increased.

\section{GLOBAL HEALTH PROBLEM LIST}

In assessing the barriers to dementia diagnosis and care in this patient, we consider the following dimensions of healthcare access, the lack of which contribute to underdiagnosis, delayed diagnosis and inadequate care in China as follows: ${ }^{3435}$

- Accessibility of healthcare centres and specialist healthcare providers. $^{172355}$

- Availability of doctors, healthcare workers and memory clinics focused on dementia..$^{183233}$

- Affordability of escalating costs of dementia care. ${ }^{11} 33$

- Adequacy of available dementia care services for community and long-term facility-based care. ${ }^{18} 55$

- Acceptability of health services for dementia diagnosis. 17335657

- Awareness of dementia as a condition. 335859

\section{GLOBAL HEALTH PROBLEM ANALYSIS}

Barriers to healthcare access as described in this report are experienced by many communities worldwide; however they are more acutely experienced in China due to the geographical size of the country, the escalating dementia prevalence along with the ageing population, and socio-cultural effects of stigma and lack of dementia awareness as discussed below.

\section{Accessibility}

Accessibility of healthcare centres and specialists providing dementia diagnosis and care in China is limited, especially in more rural areas with most of the specialised neurology or memory clinics in larger cities requiring long-distance travel to 
attend. ${ }^{17233233}$ While attempts have been made to increase available memory clinics in hospital outpatient neurology departments, these are mainly still only in the larger cities. ${ }^{32}$ This patient only received a formal diagnosis in the advanced stages of her disease after having to travel over 400 miles, ${ }^{36}$ an almost 8-hour journey by car, to an acute hospital in Beijing, due to lack of access to dementia specialists and screening in her more rural area. ${ }^{17}$ In our experience, it is also the general perception among families that the best medical care in China is in large cities like Beijing. Lack of access to a formal dementia diagnosis is a reality for many families in China, and with the predicted escalation in dementia prevalence, it is a hefty expectation that there will be sufficient personell and healthcare infrastructure resources to provide memory clinic assessments, including cognitive testing, laboratory tests and brain imaging as would be expected in better resourced countries. ${ }^{26}{ }^{60}$ However, in terms of early screening for dementia, we think that tools such as the Chinese version of the 'Mini Mental State Examination', ${ }^{43}$ and the 'Noticeable Problems Checklist ${ }^{6162}$ can be implemented by allied and community health workers to assess the likelihood of dementia so that symptom-based community support for cognition, daily functioning and quality of life can be provided in the absence of, or pending, a formal diagnosis.

Long-term care provision for older people has been prioritised through policy and legislation, ${ }^{13} 1416$ and the private nursing home sector is also increasing access to long-term care in China $^{57}$; however concerns about inadequate regulation, staff training and quality of care have spurred further legislation to ensure standardised well-regulated care. ${ }^{16173363}$ Furthermore, access to specialised dementia care services within the community or long-term care facilities is still rare, especially in more rural areas. 9173364 This is further impacted by the availability of healthcare workers with specific training in dementia care and management.

\section{Availability}

There is a projected global shortage of healthcare workers including physicians, nurses, midwives and allied healthcare workers. ${ }^{7}$ In China, there are shortages of physicians, geriatricians, neurologists, psychiatrists and geriatric psychiatrists, ${ }^{65} 66$ as well as nurses, occupational therapists and physical therapists. ${ }^{66-68}$ Limited availability of healthcare workers in China is further compounded by lack of training on dementia diagnosis and care in medical schools and colleges for urban and rural physicians. ${ }^{172233}$ As a result, there is a consequent shortage of doctors confident in diagnosing dementia, prescribing relevant medications and recommending non-pharmacological interventions. ${ }^{3369}$ While elderly care facilities such as nursing homes may have increased their available occupancy based on the targets set by legislation, there is a shortage of both facility/communitybased care workers with experience or training in dementia care to provide specialised dementia care services. ${ }^{9} 1733$ An urgent need has been identified to train both professional healthcare providers and formal and informal caregivers in dementia. ${ }^{70}$ It is encouraging that the China Central Government National Fiveyear Plan for Mental Health includes stipulation on training for assessment and management of mental health disorders, with Alzheimer's disease given specific mention. ${ }^{15}$ While physicians and specialists are integral to dementia assessment, it is our opinion that expanding the dementia-capable workforce within the primary care system would increase availability of medical and allied health professionals confident in person-centred dementia assessment and care planning. Extending training opportunities in dementia care and non-pharmacological management to formal and informal care settings could expand the available pool of dementia care providers. For example, the members of our dementia social care team discussed in this report include a social worker and a therapist with a diploma in rehabilitation which included training in physiotherapy, occupational therapy and speech therapy. Both also have had previous training and experience in working with people with dementia. Approaches to collaborative care models with multidisciplinary teams should be encouraged for the potential to improve outcomes for people with dementia and reduce costs. ${ }^{71}$

In terms of availability of long-term care resources, there are a number of policies and implementation plans in place to strengthen the availability and quality of long-term facilities and care services for older people in China including the 3-tier long-term care system plan which includes (1) home-based care, (2) community-based services for support and (3) institutional care. ${ }^{163355}$ However, our experience is that there are only a few early stage dementia-specific policies or plans at a municipal, provincial or academic university level, mostly adapted from other countries, for dementia screening, support and long-term care at the care frontline. One example is a municipal government policy to increase available dementia-dedicated beds by 1000 beds in Shanghai. ${ }^{72}$ As is the case with many countries, we recognise that the everchanging political priorities at different levels of governmental structures can impact on the continuity of communications and policy formation, the discussion of which is beyond the scope of this report.

\section{Affordability}

Affordability of dementia care in China is a substantial factor with multiple impacts including potential loss of work for those who have to leave their jobs to care for their family members, the need for sufficient income or health insurance to cover the costs of informal or formal care and increasing costs on healthcare services, though insurance coverage for dementia is limited. ${ }^{11} 33$ In this case, the patient's husband was still working and paid for all the informal carer, diagnosis, nursing home and social team care expenses through his income and savings. However, many families may not be able to afford escalating dementia care costs. In 2015 it was estimated that the annual socioeconomic cost per person with Alzheimer's disease was US\$19 144.36, while the average per capita household income in China in 2015 was about US\$3542.93 (21 966.2 Yuan). ${ }^{73} 74$ In China, over $80 \%$ of costs are carried by people with dementia and their families through their own funds or through health insurance. ${ }^{11}$ A study in 2010 indicated that most available dementia care in China is in the informal sector which accounted for $81.3 \%$ (about US $\$ 38.4$ billion) of the total national estimated costs for dementia. ${ }^{1133}$ Nursing home care accounted for $12.8 \%$ (about US\$6 billion) spend. ${ }^{11}$ Currently in China, there is no national government funding provided for home-based or communitybased dementia care services much of which are paid for outof-pocket or by health insurance for those who have insurance cover. $^{33} 75$ Our experience is that on a regional level in different cities there may be some funding for 'severe conditions'; however there is very little government funding for institutional dementia care with the only funding being provided to some hospitals with dementia wards and limited nursing homes. Access to government-funded nursing homes is very limited to only those with no resources and no alternative access to care through family support or finance. ${ }^{76}$ 


\section{Adequacy}

Adequacy of dementia service design and care within residential and nursing home facilities for people with dementia is an ongoing concern. ${ }^{33}$ In our experience, we have met a number of families who have withdrawn their parents from facilities due to dissatisfaction with the quality of care. We have noted in working with some facilities that they are short-staffed, have few resources, supports and programmes for people with dementia and staff have little to no training in dementia care. ${ }^{33}$ Despite having a dedicated dementia ward, the facility to which the patient in the report was admitted had no staff trained in dementia care, nor did they have the services of a dietitian or a speech and language therapist to advise on improving the patient's nutritional intake or conduct a swallow assessment to ensure safe food consumption and consistency. However, the rehabilitation specialist on the social care team did have suitable training for swallow assessments and was able to advise on nutritional improvements. Within community or facility settings, there is often inconsistency of a central point for care coordination for people with dementia which can contribute to poorer outcomes; however, appointing a key care coordinator can help overcome barriers to care. ${ }^{77}$ In this case, the social worker acted as the central point of care coordination and facilitated improved communication and understanding of the patient's needs, abilities and neuropsychiatric symptom triggers along with appropriate non-pharmacological interventions with other nursing home staff members and the patient's family. The social care team also provided training to nursing home facility staff on how to communicate with people with dementia, assess potential triggers for neuropsychiatric symptoms and deliver non-pharmacological interventions that stimulate the five senses with the aim of addressing and where possible reducing neuropsychiatric symptoms. There needs to be an increase in health and social care provider recruitment and training in management of dementia and symptoms from both a pharmacological and non-pharmacological perspective to facilitate improved diagnosis, care coordination and management of people with dementia. ${ }^{33}$ Burden on the healthcare system could be alleviated by promoting multidisciplinary, collaborative care and training further allied healthcare workers, formal and informal carers in person-centred dementia care. ${ }^{3371}$

\section{Acceptability}

Acceptability of health services is a term which has various definitions. ${ }^{56}$ In the context of dementia in China, we view acceptability and awareness to be closely correlated with dementia acceptance on both a social and national level. Social acceptability of dementia diagnosis and treatment in China is impacted by the significant negative cultural stigma of dementia for both the person with the disease and the family. ${ }^{1733}$ The Chinese term for dementia translated literally into English would be considered derogatory, reflecting the stigma and discrimination that people with dementia and their families can face. ${ }^{33}$ Fear of discrimination or institutionalisation may be personal barriers to seeking and accepting a dementia diagnosis. ${ }^{17}$ In China there is a cultural priority of wanting to live at home for as long as possible, which is further enhanced by a sense of family duty to care for aged family members and encouraged on a local level. ${ }^{1933}$ However, changing socioeconomic environments mean that family members, many of whom may have no siblings to share the responsibility of care due to the former 'one-child' policy, may not be able to care for an ageing parent at home due to the need to continue work, sometimes in a different city or region. ${ }^{33}$ This, in turn, may contribute to social isolation, both a risk factor for and symptom of dementia. ${ }^{38}$ The options for care that remain are to give up work in order to care for a relative, pay for care in their own home or admit the person with dementia to a nursing home. Accepting formal care at home may be limited by the person's own beliefs which may lead them to perceive formal care as potentially threatening to their ongoing desire to live independently at home. ${ }^{78}$ In terms of acceptance of dementia at a national level, the WHO and Alzheimer's Disease International set out a 6-stage 'Acceptance of Dementia' model to frame the stages of national acceptance which include stage 1, ignoring the problem; stage 2, some awareness; stage 3 , building dementia infrastructure; stage 4 , advocacy efforts; stage 5, policies and dementia plans or strategies; stage 6 , normalisation. ${ }^{33}{ }^{57}$ China is still in the lower stages indicating the significant need for community education and public health literacy campaigns to improve health literacy on dementia in China. ${ }^{5758}$

\section{Awareness}

Dementia awareness is significantly lacking in China where the symptoms of dementia are considered by many to be the normal consequences of ageing, rather than a disease. ${ }^{335859}$ Lack of awareness on the impact of dementia and of appropriate available resources for diagnosis, treatment and support contribute to delayed diagnosis. ${ }^{58}$ Furthermore, the significant stigma attached to dementia in China needs to be addressed through community education, as the fear of a diagnosis of dementia may further contribute to the reluctance for people with symptoms of dementia, or their families to access diagnosis. Education for people with dementia, their families, caregivers and communities should focus on understanding the effects of dementia and guidance on how to choose professional assessment and support. ${ }^{58}$ There are no published national or provincial public health awareness campaigns or education on dementia in China. In the context of our dementia social care service, each member of the allied healthcare staff in our social care team undertakes training and educational activities in community and facility settings with family members, care providers, neighbours, nursing home staff and community members. Further broad-reach tactics for public engagement and education on dementia employed by the social care team in China have included the use of information sharing on social media like WeChat and the promotion of massive, open, online courses from the Wicking Dementia Education and Research Centre at the University of Tasmania. ${ }^{79} 80$ Our organisation also partners with dementia and ageing organisations in China to present information on dementia at meetings and conferences. ${ }^{81} 82$

\section{CONCLUSION}

People with features of dementia need supportive dementia care to address their deteriorating condition, rehabilitate daily functioning when possible and re-establish social connection. Healthcare system barriers require further significant institutional, public and social health policy, planning and implementation strategies to meet the escalating number and needs of people with dementia in China.

Despite both global and national recognition of the need to address the increasing prevalence of dementia in China, a member of the WHO, there remain significant and numerous barriers to dementia diagnosis and care and substantial 
pressures on the national health and social care systems to cope with an escalating prevalence of dementia as illustrated in this case report. ${ }^{2591113145557}$ However, at a local level some of the barriers to adequate care were overcome by a pragmatic collaboration by the nursing home with a third-party social care organisation with experience in dementia care. The social care team were then able to implement a multicomponent, non-pharmacological intervention programme to optimise management of this patient with advanced dementia as well as provide dementia care coordination and training of nursing home staff. The improvements in activities of daily living and neuropsychiatric symptom frequency noted in this patient may be unusual for many other people at similar stages of advanced dementia. However, we think that this case illustrates how an improved care environment and intensive support helped the patient to rehabilitate some of the activities of daily living that might have been preserved with better dementia care knowledge in the home environment. The case therefore illustrates examples of some measures that can be implemented to overcome local barriers using innovation, collaboration, education and patient advocacy to address the complex care needs of people with advanced dementia. ${ }^{83} 84$

\section{Learning points}

- Escalating prevalence of dementia in low/middle-income countries like China is compounded by numerous social, cultural, political and healthcare system barriers to diagnosis and care.

- Non-pharmacological interventions as part of person-centred care and rehabilitation can improve activities of daily living and reduce neuropsychiatric symptoms of dementia.

- There is a need for innovative solutions to address the complex, specialised care needs of people with dementia especially as dementia progresses which include recruitment and training of a wider range of health and care professionals and caregivers.

- Intersectoral collaboration between organisations can facilitate pragmatic support and care coordination for people with dementia where services are lacking.

Acknowledgements The authors would like to thank Charles Young for his editorial oversight and input, and Harriet Leyland for her peer review feedback.

Contributors ZQ and AW: conception and design as well as analysis and interpretation of data; AW, VFZ, MMC: acquisition of data; ZQ: drafting the article or revising it critically for important intellectual content; ZQ, AW, VFZ, MMC: final approval of the version published; MMC: agreement to be accountable for the article and to ensure that all questions regarding the accuracy or integrity of the article are investigated and resolved.

Funding The authors have not declared a specific grant for this research from any funding agency in the public, commercial or not-for-profit sectors.

Competing interests AW, VFZ and MMC are employees of Care Visions China, the company providing the social care dementia programme. ZQ is a contracted employee of Care Visions Limited, UK.

Patient consent for publication Next of kin consent obtained.

Provenance and peer review Not commissioned; externally peer reviewed.

Open access This is an open access article distributed in accordance with the Creative Commons Attribution Non Commercial (CC BY-NC 4.0) license, which permits others to distribute, remix, adapt, build upon this work non-commercially, and license their derivative works on different terms, provided the original work is properly cited and the use is non-commercial. See: http://creativecommons.org/ licenses/by-nc/4.0/.

ORCID iD

Mark McLean Carter http://orcid.org/0000-0002-4727-9972

\section{REFERENCES}

1 Alzheimer's Association. 2019 Alzheimer's disease facts and figures. Alzheimer's \& Dementia 2019;15:321-87.

2 World Health Organization. Global action plan on the public health response to dementia 2017-2025, 2017. Available: http://www.who.int/mental_health/neurology/ dementia/action_plan_2017_2025/en/ [Accessed 1 Aug 2019].

3 Prince MJ, Wimo A, Guerchet MM, et al. World Alzheimer Report 2015 - The Global Impact of Dementia: An analysis of prevalence, incidence, cost and trends. London: Alzheimer's Disease International, 2015. https://www.alz.co.uk/research/world-report2015. (Accessed 1 August 2019).

4 G20 Summit Leaders. G20 Osaka Leaders' Declaration, 2019. Available: https://g20. org/pdf/documents/en/FINAL_G20_Osaka_Leaders_Declaration.pdf [Accessed 1 Aug 2019].

5 World Health Organization. Global strategy and action plan on ageing and health, 2017. Available: https://www.who.int/ageing/global-strategy/en/ [Accessed 1 Aug 2019].

6 Sleeman KE, de Brito M, Etkind S, et al. The escalating global burden of serious health-related suffering: projections to 2060 by world regions, age groups, and health conditions. Lancet Glob Health 2019;7:e883-92.

7 Liu JX, Goryakin Y, Maeda A, et al. Global health workforce labor market projections for 2030. Hum Resour Health 2017;15:11

8 United Nations Department of Economic and Social Affairs Population Division. World population ageing, 2017. Available: https://www.un.org/en/development/ desa/population/publications/pdf/ageing/WPA2017_Report.pdf [Accessed 1 Aug 2019].

9 World Health Organization. China country assessment report on ageing and health, 2015. Available: https://apps.who.int/iris/bitstream/handle/10665/194271/ 9789241509312_eng.pdf?sequence=1 [Accessed 1 Aug 2019].

10 Wu Y-T, Ali G-C, Guerchet M, et al. Prevalence of dementia in mainland China, Hong Kong and Taiwan: an updated systematic review and meta-analysis. Int J Epidemiol 2018:47:709-19.

11 Xu J, Wang J, Wimo A, et al. The economic burden of dementia in China, 1990-2030: implications for health policy. Bull World Health Organ 2017;95:18-26.

12 Keogh-Brown MR, Jensen HT, Arrighi HM, et al. The impact of Alzheimer's disease on the Chinese economy. EBioMedicine 2016;4:184-90.

13 China's National People's Congress. The 12th five-year plan (2011-2015) for national economic and social development, 2011. Available: https://policy.asiapacificenergy. org/node/37 [Accessed 1 Aug 2019].

14 China's National People's Congress. The 13th five-year plan for economic and social development of the people's Republic of China (2016-2020), 2019. Available: https:// policy.asiapacificenergy.org/node/2509/portal [Accessed 1 Aug 2019].

15 General Office of the State Council (China). National Mental Health Work Plan (20152020), 2015. Available: http://www.gov.cn/zhengce/content/2015-06/18/content_ 9860.htm

16 Qu M. The Legislation Evolvement of China's Elderly Care Industry, 2019. Available: http://www.tsunlaw.com/index.php?m=en\&a=publications_view\&id=806 [Accessed 1 Aug 2019].

17 Chen S, Boyle LL, Conwell Y, et al. The challenges of dementia care in rural China. Int Psychogeriatr 2014;26:1059-64.

18 United Nations Economic and Social Commission for Asia and the Pacific. Long-Term care of older persons in China, 2015. Available: https://www.unescap.org/resources/ long-term-care-older-persons-china [Accessed 1 Aug 2019].

19 Feng Z, Liu C, Guan X, et al. China's rapidly aging population creates policy challenges in shaping a viable long-term care system. Health Aff 2012:31:2764-73.

20 Wang M, Shao S, Li J, et al. The needs of informal caregivers and barriers of primary care workers toward dementia management in primary care: a qualitative study in Beijing. BMC Fam Pract 2018;19:201

21 International Federation on Ageing. China National Committee on ageing (CNCA), 2019. Available: https://www.ifa-fiv.org/partner-profiles/china-national-committee-onageing-cnca/ [Accessed 1 Aug 2019].

22 Patterson C. International Alzheimer's Disease. The world Alzheimer report 2018, the state of the art of dementia research: new frontiers, 2018. Available: https://www.alz. co.uk/research/world-report-2018 [Accessed 1 Aug 2019].

23 Chen S, Boyle LL, Conwell Y, et al. Dementia care in rural China. Ment Health Fam Med 2013;10:133-41.

24 Lang L, Clifford A, Wei L, et al. Prevalence and determinants of undetected dementia in the community: a systematic literature review and a meta-analysis. BMJ Open 2017; 7:e011146.

25 Chen R, Hu Z, Chen R-L, et al. Determinants for undetected dementia and late-life depression. Br J Psychiatry 2013;203:203-8.

26 Robinson L, Tang E, Taylor J-P. Dementia: timely diagnosis and early intervention. BMJ 2015;350:h3029.

27 Jia J, Wang F, Wei C, et al. The prevalence of dementia in urban and rural areas of China. Alzheimers Dement 2014;10:1-9.

28 Zhang $\mathrm{Y}, \mathrm{Xu}$ Y, Nie $\mathrm{H}$, et al. Prevalence of dementia and major dementia subtypes in the Chinese populations: a meta-analysis of dementia prevalence surveys, 1980-2010. J Clin Neurosci 2012;19:1333-7. 
29 Cammisuli DM, Danti S, Bosinelli F, et al. Non-Pharmacological interventions for people with Alzheimer's disease: a critical review of the scientific literature from the last ten years. Eur Geriatr Med 2016;7:57-64.

30 de Oliveira AM, Radanovic M, de Mello PCH, et al. Nonpharmacological interventions to reduce behavioral and psychological symptoms of dementia: a systematic review. Biomed Res Int 2015;2015:218980

31 Scales K, Zimmerman S, Miller SJ. Evidence-Based nonpharmacological practices to address behavioral and psychological symptoms of dementia. Gerontologist 2018;58:S88-102.

32 Jia J, Zuo X, Jia X-F, et al. Diagnosis and treatment of dementia in neurology outpatient departments of general hospitals in China. Alzheimers Dement 2016;12:446-53.

33 Chen Z, Yang X, Song Y, et al. Challenges of dementia care in China. Geriatrics 2017;2:pii: E7.

34 Jacobs B, Ir P, Bigdeli M, et al. Addressing access barriers to health services: an analytical framework for selecting appropriate interventions in low-income Asian countries. Health Policy Plan 2012;27:288-300.

35 Saurman E. Improving access: modifying Penchansky and Thomas's theory of access. $J$ Health Serv Res Policy 2016:21:36-9.

36 Maps GG, 2019. Available: https://www.google.com/maps [Accessed 1 Aug 2019].

37 Erol R, Brooker D, Peel E, Alzheimer's Disease International. Women and dementia: a global research review, 2015. Available: https://www.alz.co.uk/sites/default/files/pdfs/ Women-and-Dementia.pdf [Accessed 1 Aug 2019].

38 Livingston G, Sommerlad A, Orgeta V, et al. Dementia prevention, intervention, and care. Lancet 2017;390:2673-734.

39 Kostev K, Hadji P, Jacob L. Impact of osteoporosis on the risk of dementia in almost 60,000 patients followed in general practices in Germany. J Alzheimers Dis 2018:65:401-7.

40 Chang K-H, Chung C-J, Lin C-L, et al. Increased risk of dementia in patients with osteoporosis: a population-based retrospective cohort analysis. Age 2014;36:967-75.

41 Morris JC. The clinical dementia rating (CDR): current version and scoring rules. Neurology 1993;43:2412-4.

42 Reisberg B, Ferris SH, de Leon MJ, et al. Global deterioration scale (GDS). Psychopharmacol Bull 1988;24:661-3.

43 Katzman R, Zhang MY, Wang ZY, et al. A Chinese version of the Mini-Mental state examination; impact of illiteracy in a Shanghai dementia survey. J Clin Epidemiol 1988:41:971-8.

44 Folstein MF, Robins LN, Helzer JE. The Mini-Mental state examination. Arch Gen Psychiatry 1983;40:812.

$45 \mathrm{Li} \mathrm{H}$, Jia J, Yang Z. Mini-Mental state examination in elderly Chinese: a populationbased normative study. J Alzheimers Dis 2016;53:487-96.

46 Abraha I, Rimland JM, Trotta FM, et al. Systematic review of systematic reviews of non-pharmacological interventions to treat behavioural disturbances in older patients with dementia. The SENATOR-OnTop series. BMJ Open 2017:7:e012759.

47 Cowl AL, Gaugler JE. Efficacy of creative arts therapy in treatment of Alzheimer's disease and dementia: a systematic literature review. Activities Adaptation and Aging 2014;38:281-330

$48 \mathrm{Ng}$ QX, Ho CYX, Koh SSH, et al. Doll therapy for dementia sufferers: a systematic review. Complement Ther Clin Pract 2017;26:42-6.

49 Mitolo M, Tonon C, La Morgia C, et al. Effects of light treatment on sleep, cognition, mood, and behavior in Alzheimer's disease: a systematic review. Dement Geriatr Cogn Disord 2018;46:371-84.

50 Mitchell G, Agnelli J. Non-Pharmacological approaches to alleviate distress in dementia care. Nurs Stand 2015;30:38-44.

51 Alzheimer's Society. Talking therapies (including counselling, psychotherapy and CBT)2015 26 October 2018.. Available: https://www.alzheimers.org.uk/sites/default/ files/pdf/talking_therapies_including_counselling_psychotherapy_and_cbt.pdf [Accessed 1 Aug 2019].

52 Keller HH. Improving food intake in persons living with dementia. Ann N Y Acad Sc 2016;1367:3-11.

53 Wade DT, Collin C. The Barthel ADL index: a standard measure of physical disability? Int Disabil Stud 1988; 10:64-7.

54 James BD, Wilson RS, Capuano AW, et al. Cognitive decline after elective and nonelective hospitalizations in older adults. Neurology 2019;92:e690-9.

55 Wang S, Cheung DSK, Leung AYM. Overview of dementia care under the three-tier long-term care system of China. Public Health Nurs 2019:36:199-206.

56 Sekhon M, Cartwright M, Francis JJ. Acceptability of healthcare interventions: an overview of reviews and development of a theoretical framework. BMC Health Serv Res 2017;17:88.

57 World Health Organization. Alzheimer's Disease International. Dementia: a public health priority, 2012. Available: https://www.who.int/mental_health/publications/ dementia_report_2012/en/ [Accessed 1 Aug 2019].

58 Zhang H, Loi SM, Zhou Shu'aijun, Zhou S, et al. Dementia literacy among communitydwelling older adults in urban China: a cross-sectional study. Front Public Health 2017:5:124
59 Zhao M, Lv X, Tuerxun M, et al. Delayed help seeking behavior in dementia care: preliminary findings from the clinical pathway for Alzheimer's disease in China (CPAD) study. Int Psychogeriatr 2016;28:211-9.

60 National Guideline Alliance (UK). Dementia: assessment, management and support for people living with dementia and their carers. June 2018. Available: https://www. nice.org.uk/guidance/ng97/evidence/full-guideline-pdf-4852695709 [Accessed 1 Aug 2019].

61 Laybourne A, Livingston G, Cousins S, et al. Carer coping and resident agitation as predictors of quality of life in care home residents living with dementia: managing agitation and raising quality of life (MARQUE) English national care home prospective cohort study. Int J Geriatr Psychiatry 2019;34:106-13.

62 Levin E. Noticeable problems checklist. London: National Institute for Social Work, 1989

63 World Health Organization. Neurological disorders: public health challenges, 2006. Available: https://www.who.int/mental_health/publications/neurological_disorders ph_challenges/en/ [Accessed 1 Aug 2019]

64 Wu C, Gao L, Chen S, et al. Care services for elderly people with dementia in rural China: a case study. Bull World Health Organ 2016;94:167-73.

65 International Psychogeriatric Association. The psychogeriatric workforce in China: challenges for the future, 2019. Available: https://www.ipa-online.org/about/ipanews-and-media/workforce-issues/the-psychogeriatric-workforce-in-china-challengesfor-the-future [Accessed 1 Aug 2019].

66 Wu Q, Zhao L, Ye X-C. Shortage of healthcare professionals in China. BMJ 2016;354:i4860

67 Zhou M, Zhao L, Kong N, et al. What caused seriously shortage of Chinese nurses? Iran J Public Health 2018:47:1065-7.

68 Schoeb V. Healthcare service in Hong Kong and its challenges. China perspectives, 2016. Available: http://journals.openedition.org/chinaperspectives/7118 [Accessed Aug 2019]

69 Liu JYW, Lai C, Dai D, et al. Attitudes in the management of patients with dementia: comparison in doctors with and without special training. East Asian Arch Psychiatry 2013;23:13-20.

$70 \mathrm{Xu} \mathrm{L}$, Hsiao H-Y, Denq W, et al. Training needs for dementia care in China from the perspectives of mental health providers: who, what, and how. Int Psychogeriatr 2018:30:929-40.

71 Galvin JE, Valois L, Zweig Y. Collaborative transdisciplinary team approach for dementia care. Neurodegener Dis Manag 2014;4:455-69.

72 District Civil Affairs Bureau, Finance Bureau. On the issuance of "dementia care beds in setting work program (Trial)". Shanghai China Fu Fa. 2018;No. 11. Available: http:// mzj.sh.gov.cn/gb/shmzj/node8/node194/u1ai45643.html

73 Jia J, Wei C, Chen S, et al. The cost of Alzheimer's disease in China and re-estimation of costs worldwide. Alzheimers Dement 2018;14:483-91.

74 National Bureau of Statistics China. China statistical Yearbook 2016: per capita income and consumption expenditure nationwide, 2016. Available: http://www.stats. gov.cn/tjsj/ndsj/2016/indexeh.htm [Accessed 1 Aug 2019].

75 Gallagher-Thompson D, Tzuang Y, Au A, et al. Families dealing with dementia: Insights from China, Hong Kong, and Taiwan. In: Karen E, Shripad T, eds. In aging Asia: the economic and social implications of rapid demographic change in China, Japan, and South Korea. Stanford, CA, USA: The Walter H. Shorenstein Asia-Pacific Research Center, 2010.

76 Cheng S-T, Lum T, Lam LCW, et al. Hong Kong: embracing a fast aging Society with limited welfare. Gerontologist 2013:53:527-33.

77 Backhouse A, Ukoumunne OC, Richards DA, et al. The effectiveness of communitybased coordinating interventions in dementia care: a meta-analysis and subgroup analysis of intervention components. BMC Health Serv Res 2017:17:717.

78 Stephan A, Bieber A, Hopper L, et al. Barriers and facilitators to the access to and use of formal dementia care: findings of a focus group study with people with dementia, informal carers and health and social care professionals in eight European countries. BMC Geriatr 2018:18:131.

79 Wicking Dementia Research and Education Centre at the University of Tasmania. Understanding dementia MOOC, 2019. Available: https://www.utas.edu.au/wicking/ understanding-dementia [Accessed 1 Aug 2019].

80 Wicking Dementia Research and Education Centre at the University of Tasmania. Preventing dementia MOOC, 2019. Available: https://www.utas.edu.au/wicking/ preventing-dementia [Accessed 1 Aug 2019]

81 Memory Health 360 Project; PRNewswire. Friendship big ship set sail - China's cognitive friend project officially launched, 2016. Available: https://www.prnasia.com/ story/151602-1.shtml [Accessed 1 Aug 2019].

82 ChinaAid. [The First Official Report of the Third China Pension Industry Lujiazui Summit!] 2019.

83 Douthit NT, Biswas S, Education GH. Global health education and advocacy: using BMJ case reports to tackle the social determinants of health. Front Public Health 2018;6:114.

84 Rowthorn V, Olsen J. All together now: developing a team skills competency domain for global health education. J Law Med Ethics 2014;42:550-63. 


\section{Global health}

Copyright 2020 BMJ Publishing Group. All rights reserved. For permission to reuse any of this content visit https://www.bmj.com/company/products-services/rights-and-licensing/permissions/

BMJ Case Report Fellows may re-use this article for personal use and teaching without any further permission.

Become a Fellow of BMJ Case Reports today and you can:

- Submit as many cases as you like

- Enjoy fast sympathetic peer review and rapid publication of accepted articles

Access all the published articles

Re-use any of the published material for personal use and teaching without further permission

Customer Service

If you have any further queries about your subscription, please contact our customer services team on +44 (0) 2071111105 or via email at support@bmj.com.

Visit casereports.bmj.com for more articles like this and to become a Fellow 